\title{
The Creation Manifestation of Tie-dyeing Craft in Modern Fashion Design
}

\author{
Yanli $\mathrm{Hu}$ \\ The Fashion Design and Management branch \\ Jiangxi Institute of Fashion Technology \\ Nanchang, China \\ 190878023 @qq.com
}

Keywords: Craft Creation; the Style of Tie-dyeing; the Modern Application

\begin{abstract}
The tie-dyeing art has experienced a perfect evolution from the traditional craft to the modern application until today. The tie-dyeing art is full of resplendence and glamour due to both the aesthetic perception retaining of traditional craft and the creation and the blending of modern science. The pattern of tie-dyeing is full of excellent color match, which is natural and unsophisticated; the style of tie-dyeing is rich and coordinate. The application of tie-dyeing contains not only in modern clothes and costume accessories, but also in ornamentation, home textiles and soft furniture. The craft of tie-dyeing makes the combination of elegance and time in fashion design.
\end{abstract}

\section{Introduction}

The manifestation form of today's tie-dyeing has become more and richer until now. It can be found not only in clothe, textile, home furnishing, but also in indoor soft decoration. Vegetation patterns were usually chosen in traditional tie-dyeing patterns. Today, the choice of patterns panders to the trend of the time and the aesthetic taste of today's people. Therefore, a new type of tie-dyeing which experienced from concrete to abstract is appearing to meet the needs of the consumers.

Besides, other manifestation forms such as the modern craft method, weaving and embroidery are all considered when the tie-dyeing craft is created. The production of tie-dyeing demonstrates an aesthetic perception through the melting of all manifestation forms.

\section{The Application and Manifestion of the Pattern}

The traditional patterns of tie-dyeing have many manifestations, for example, natural style animals and dermatoglyphic patterns of many plants and flowers.

The patterns of plants and animals were largely used in traditional dermatology pattern fashion design. Butterfly flower dermatoglyphic pattern, it has the form of free punctiform, is the classic patterns in traditional tie-dyeing patterns.

Swing dyeing makes the patterns of tie-dyeing in industrial looks more natural and the jumpy rhythm which is possessed by this design. It is full of the sense of convulse in visual effect. (Fig. 2)

The creation of modeling combined the model of abstract sense with the traditional patterns of tiedyeing, which overthrew the binding to the style and promote the

Assembly in color match. This overall creation change will bring people a new state from all kinds of angles.(Fig. 1) 


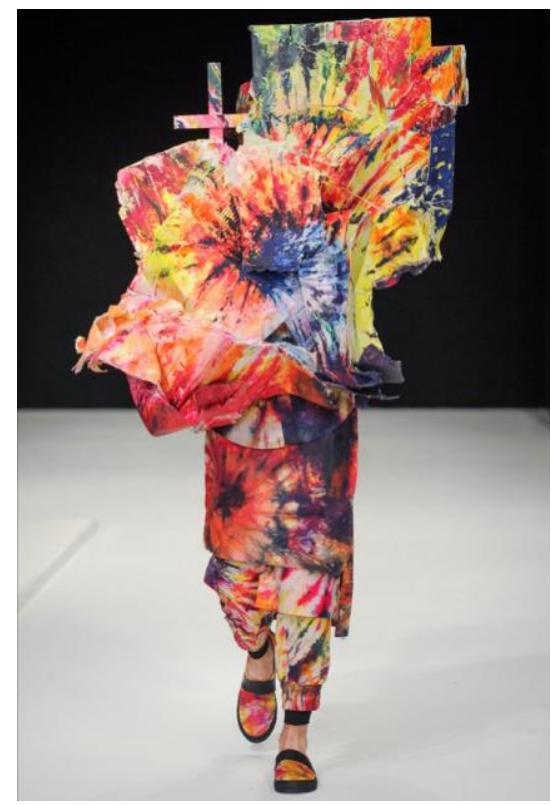

Figure 1. Color dyeing

Modern tie-dyeing art in fashion design combined with the digital arts, digital spray colors, and computer embroidery has many manifestation forms. Generally speaking, the application of tiedyeing technology contains as follows: the figured silk fabrics such as stitch, wring, wrap and mingle. The embroider can form the effect of blocking and make the production have a gorgeous color and exquisite patterning. Dip dyeing and is possessed by this design. It is full of the sense of convulse in visual effect. (Fig. 2)

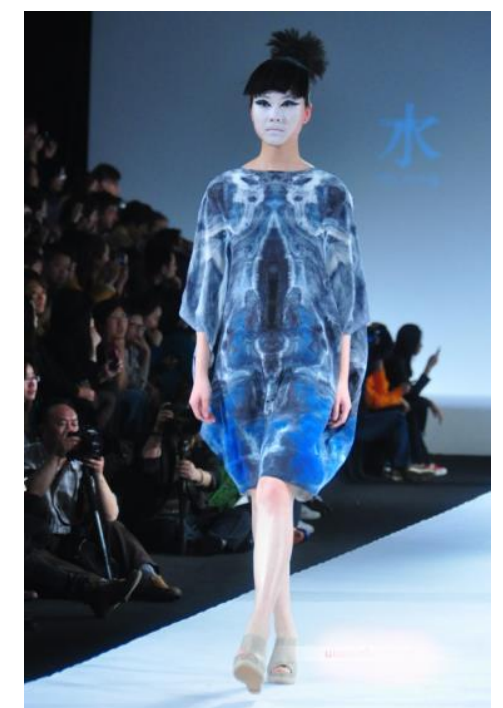

Figure 2. Digital art

The art of modern tie-dyeing has broken through the limit of traditional hand-made technology; it has greatly outnumbered the technology of traditional hand-made method. Some pure science technology such as computer digital craft, computer embroidery craft and laser art are all considered to use in modern tie-dyeing. These technologies are used in all living fields.

The classic fabric of traditional tie-dyeing craft characterizes cotton-linen natural fabric. The fabric is simplicity but the feeling of brightness is not so strong which brings great limit to the application of tie-dyeing's use in different fashion design.

On the creation and change of the tie-dyeing in craft, the tie-dyeing craft can be used in all kinds of fabrics randomly. Such as jeans fabric, light perception silk, leather, chemical fabrics, suede wool fabrics, lycra fabrics. All these fabrics break through the limit to the tie-dyeing fabric only in the application of natural fiber. The fabric of modern feeling will gain the beauty-appreciation meaning 
of better than better on the traditional tie-dyeing, and show the application of modern tie-dyeing craft to the fashion design and the creation in the fabrics.

\section{The Application and Reference of the Color}

The color of tie-dyeing in modern fashion design is not limit to the traditional simplicity blues, but catch up with the change of popular colors. Natural material has also become the thought fountain in the art color creation of modern tie-dyeing. For example, the color of the sea is used in the manifestation of tie-dyeing, the harmony color of the sea makes the garment looks much charm. Different and characteristic territory folk tinges are also the reference of tie-dyeing. The character of national color: bright, full-bodied, simplicity and affinity, make the craft of tie-dyeing more rich. In overall color match, classic tie-dyeing design contains as follows:

The match of the same color, which can also be understood the same type color. It has only one color, but the color will change according to the lightness gradually. The whole color verges to unification and harmony, in this situation, the contrasting color can be used, complementary color can be used to restore in small areas, to adjust the monotony of the same color. (Fig. 3)

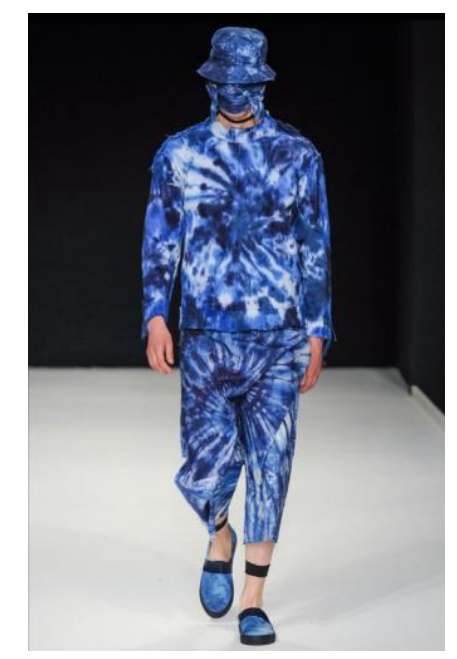

Figure 3. The same color

The match analogous color is characterized by the similar color match. Melting the adverse color to get to the harmony and abide by the regularity of people's eyes. It is on the base of the same color, and has some slight change in color match compared with the above. It can be reached through the change of the light and deep color; it can also be reached through the adding of a relevant senior color to the essential color to form harmony match. (Fig. 4) 


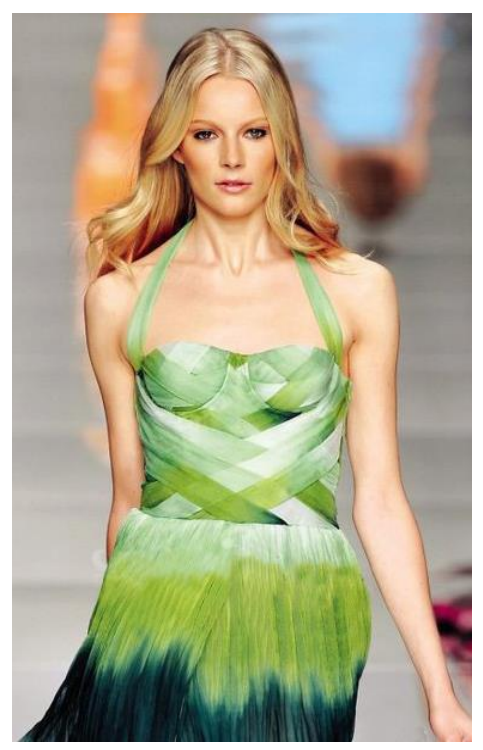

Figure 4. The similar color

Comparing with the color match, it is the classic color match through the strong contrast. In this color match, the clash in color is intensive, and the difference of color visual is great. In the whole, the color match is bold, bright and active. Therefore, when it comes to the color match, it has the requirements to the brightness and lightness, and the needs to use the same color to get to the harmony.

\section{The Application of the Fabric}

The art of modern tie-dyeing has broken through the limit of traditional hand-made technology, and it has greatly outnumbered the technology of traditional hand-made method. Some pure science technology such as computer digital craft, computer embroidery craft and laser art are all considered to use in modern tie-dyeing. These technologies are used in all living fields.

The classic fabric of traditional tie-dyeing craft characterizes cotton-linen natural fabric. The fabric is simplicity but the feeling of brightness is not so strong which brings great limit to the application of tie-dyeing's use in different fashion design.

On the creation and change of the tie-dyeing in craft, the tie-dyeing craft can be used in all kinds of fabrics randomly. Such as jeans fabric, light perception silk, leather, chemical fabrics, suede wool fabrics, lycra fabrics. All these fabrics break through the limit to the tie-dyeing fabric only in the application of natural fiber. The fabric of modern feeling will gain the beauty-appreciation meaning of better than better on the traditional tie-dyeing, and show the application of modern tie-dyeing craft to the fashion design and the creation in the fabrics.

\section{The Application and the Reference of Modern Clothes to the Style of Tie-dyeing}

Nowadays, the culture of tie-dyeing is very popular, and it has many forms to show the craft of tie-dyeing. The model of the patterns is elegant; the combination of the color is bold; the change of the style is unique and obvious, which all make the tie-dyeing craft become more perfect. The designer endowed new artistic appeal to the tie-dyeing through the change of creation character and the effect of different decoration style. Next, researchers will introduce different classic style aesthetic features of tie-dyeing.

The Traditional Realist Style. The realist style can be classified into the creation and the realist manifestation of the tie-dyeing. In traditional craft, the point, line and surface were used to construct the patterns. The pattern and the style are full of traditional feeling. Of course, the realist style is used mostly in the traditional classic fashion design.

The Abstract Enjoyable Style. The abstract tie-dyeing style has very strong manifestation in the creation. When it comes to the manifestation of tie-dyeing creation, researchers need to use some 
offhand craft method, such as stacking, banding and tying. Natural texture effect and free unrestrained abstract pattern can be created through these methods, it is also the key character of the abstract enjoyable style.

The Romantic Garden Country Style. Country style inherits the natural simplicity and aesthetic perception, which caters to the lives of what people are pursuing. The patterns of tie-dyeing and craft decoration romantic garden country style can be easily found in the natural and random leisure wears.

Personal Fashion Style. Today, the tie-dyeing not only can be used in the traditional fashion design, but also has become the elements of fashion design. Especially the creation of patterns, the bold construction of the color, the aesthetic form, all of these make the designer has more free creation space and thought. The bold and abstract pattern color makes the tie-dyeing become more and more popular, which is used suitably in personal unique fashion design.(Fig. 5)

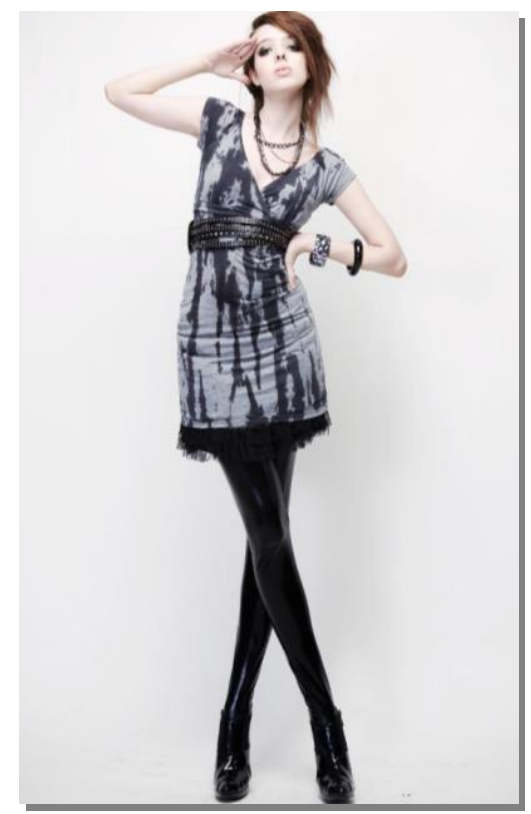

Figure 5. Personal fashion style

The Traitorous Street Style. In the 1960s, a traitorous street culture was appearing among the young people, which is opponent towards the traditional aesthetics, this new action emphasized the combination of different elements to form the effect of not harmony form. Therefore, modern tiedyeing craft is also affected by the culture of the street and the traitorous ideological trend. Random graffiti was also used in the tie-dyeing. Personal and abstract color visual feeling is full of the society, and patterns have got a great application. Combining the development of modern electric technology, digital the inkjet printing flowers, free hand drawing, and clinch bolt are appearing gradually, which embodied the conflict of the street culture elements and the random creation effect. (Fig. 6) 


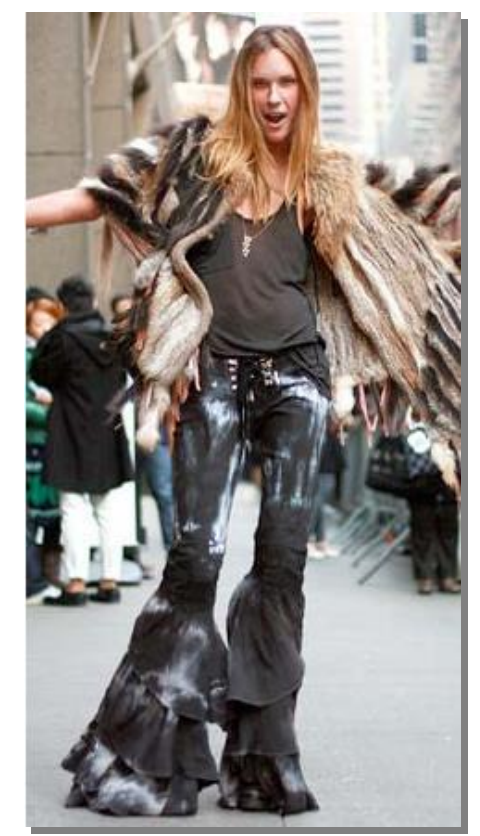

Figure 6. The street style

\section{The Application Significance in the Modern Fashion Design of the Tie-dyeing}

When it comes to today's development of the tie-dyeing, it has experienced a perfect evolution from the traditional craft to the modern application. The tie-dyeing art is full of resplendence and glamour due to not only the aesthetic perception retaining of traditional craft, but also the creation and the blending of modern science. Many unique folk traditional craft were emerging during the long culture development history. To the today of the history, people are inheriting and continuing the traditional culture, and these cultures are worth to cherish and keep. There is no doubt that these cultures will bring splendid radiance and the tie-dyeing is one of the most wonderful treasures of traditional culture. The pattern of the tie-dyeing is natural and perfect; excellent and simplicity; the style of the tie-dyeing is rich and harmony. Just because of these merits, the tie-dyeing is concerned and loved by people all the time, and it will be inherited from generation to generation. The application of the tie-dyeing will contain not only in the modern fashion design, but also in the decoration, home textiles and soft furniture. I will say it is a good way to inherit and develop the tiedyeing, let the characters of the nationality feeling and fashion has a perfect melting. Especially the appearing of the electric, a gentle and traditional craft taste are found and touched in modern fashion design. It is a combination of gentle and time.

The traditional tie-dyeing is one of the ancient crafts in China folk, and it is the culture treasure of the Chinese nation. It has experienced a glorious history in the long development. In this process, though it experienced standstill and forgetting, it gained the concern and love by all the people of the world through its adamant art charm. The tie-dyeing is popular all over the world due to its simple and easily operated craft; the color match with accident and change. Of course, the art effect of free creation shows the free aesthetic consciousness and unique art charm of the tie-dyeing. Put eyes on the development of the tie-dyeing, it is a perfect pursue of melting the traditional craft with modern craft; it meets the needs of people's pursuing the new and the change.

\section{The Creation Manifestation of Tie-dyeing in Modern Fashion Design}

Modern tie-dyeing craft has a comprehensive craft effect towards our visual feeling, combined the traditional tie-dyeing method with the method of the craft and the staining technology. It can also be called Dyeing and Finishing. In order to create the craft of the tie-dyeing, new craft and method of dyeing were recommended into the traditional craft, to make the tie-dyeing have new changes in pattern design, color match and style characters, to form the features of modern tie-dyeing. Modern 
tie-dyeing considered the personal feeling of the time and the traditional charm in modern fashion design, putting them together, and it can develop the value in the fashion design and the wide space to its future through the introduction of the tie-dyeing. Now let's talk about the difference and the creation of the fabric between the traditional and the modern tie-dyeing. Compared with the traditional tie-dyeing, the modern tie-dyeing has possessed the craft characters of electromechanization, catching up the time space in the beauty-appreciation. Many fashion styles can be designed and loved by a lot of people through the creation of the patterns and the change of the dyeing. Modern tie-dyeing is the coalesce of the ancient and the modern, possessing the personal style and all new craft creation. After the adding of these new elements, the characters of the traditional tie-dyeing were kept in new fashion design. Generally speaking, the traditional tie-dyeing is pure and simple, fine and smooth, classic and frugal. As you know, the designer applied them together in the fashion design, combining with the modern elements to create new tie-dyeing craft.

Researchers can know that many personal works are designed under the effect and the need of modern fashion people with the tie-dyeing, and these works are unique and popular among the young people. In these works, many high-technology creations were added into the tie-dyeing craft. In the past, the tie dyeing was used in the cotton linen which was very simplicity, after the use of the tiedyeing, and it gave a sense of leisure. There are many forms to create the fabrics, whatever style fabrics, nature or lining, such as the personal mental fabrics, gentle bright fabrics, unique texture fabrics, all can be used in the tie-dyeing. The decoration of tie-dyeing has broken the strain of sole fabric, it can be found in different seasons fashion design. Just because the creation technology and the aesthetic form, the tie-dyeing has become the most important design method and craft manifestation.

\section{Conclusion}

Today, people pursue their personal characters more than ever before with the development of the time, and the tie-dyeing emerged under the needs of the market. Under the process of the change from the tradition to the modern, the designer found a rich element and method to meet the needs of people's pursue towards the unique characters. The tie-dyeing has the sense of traditional culture. The traditional tie-dyeing patterns were chose according to the traditional patterns. Therefore, the tiedyeing concentrated the traditional culture. That's the value of the traditional craft. Researchers should cherish and make use of it. Especially in the fashion design, researchers should make full use of the traditional craft to serve the modern fashion design. After careful research on the traditional culture, researchers know that it emphasized the artistic conception not just the simple drawing. Therefore, when it comes to the application of the tie-dyeing in the fashion design, researchers should not only emphasize the form of the patterns but also the ceremony of the whole decoration. Talking about the inheriting of the traditional culture, researchers should not only grasp the form and the connotation of the culture, but also the conclusion of the traditional beauty-appreciation rule. Understanding the beauty-appreciation rule, the designer will know the meaning and the connotation of different combination about traditional culture elements. What's more, the beauty-appreciation rule should be applied in the modern fashion design through the combination of the tradition and the modern culture elements to show the Chinese traditional charm.

\section{References}

[1] H. Liang, Gu Ming, Liu Suqiong. The design and the application of the art dyeing craft. [M]. Beijing: China textile press.

[2] L. Daoguang. The research of Chinese blue dyeing craft and its industrialization. [M]. Nanjing: the press of south-east university, 2010.3:40

[3] Y. Tao. Modern tie-dyeing craft [M]. Shanghai: the press of shanghai Jiaotong university, 2010:24-26. 
[4] L. Jialiu. Decoration Patterns [M]. Beijing: high education press, 2008.3:78-81.

[5] X.Wen. The patterns of garments [M]. Beijing: China textile press.2008. 1:119-122.

[6] F.Kuanjun. The technology of digital inkjet printing. [M]. Beijing: China textile press.2008. $1: 80$.

[7] W. Qing. Garment dyeing [M]. Beijing: chemical industry press, 2009.7:55-56.

[8] W. Chun-sheng, H.xiaoxiang. Green clothing design concept and strategy [J]. Journal of silk, $2004(5): 8-10$

[9] X.WenWe are clothing design [M]. Beijing: China textile press, 2008.1:119-122.

[10]T.XueMei H.Kang. Pattern design teaching [M]. Beijing: higher education press, 2009.12:47' 